\title{
Correlation between Clinical Symptoms and Lab Tests with Endoscopic Severity Indexes in Patients with Inflammatory Bowel Diseases
}

\author{
Sanaz Soleymani ${ }^{1}$, Azadeh Moradkhani ${ }^{1}$, Masoumeh Eftekhari ${ }^{2}$, Fatemeh Rahmanian ${ }^{3}$, Seyed Hamid Moosavy ${ }^{4, *}$
}

1. Department of Internal Medicine, Shahid Mohammadi Hospital, Hormozgan University of Medical Sciences, Bandar Abbas, Iran

2. Department of Internal Medicine, Hazrat Abolfazl Hospital, Minab, Iran

3. Hormozgan University of Medical Sciences, Bandar Abbas, Iran

4. Department of Gastroenterology, Shahid Mohammadi Hospital, Hormozgan University of Medical Sciences, Bandar Abbas, Iran

\section{* Corresponding Author:}

Seyed Hamid Moosavy, MD

Department of Gastroenterology, Shahid Mohammadi Hospital, Hormozgan University of Medical Sciences, Bandar Abbas, Iran

Tel: + 987633338670

Fax: +987632239820

Email: seyedhamidmoosavy@gmail.com

Received: 20 Jan. 2020

Accepted: 11 Jun. 2020

\section{ABSTRACT}

\section{BACKGROUND}

The Crohn's Disease Endoscopic Index of Severity (CDEIS) and the Ulcerative Colitis Endoscopic Index of Severity (UCEIS) are two validated endoscopic scoring system to evaluate patients with inflammatory bowel diseases (IBD). We conducted this study to evaluate the correlation between clinical symptoms and lab tests with these indexes in patients with Crohn's disease (CD) and ulcerative colitis (UC).

\section{METHODS}

In this analytical study, 373 consecutive patients referred to Shahid Mohammadi Hospital with IBD were enrolled. All patients underwent complete ileocolonoscopy, and the endoscopic severity indexes (CDEIS and UCEIS) were calculated, and their relation with clinical symptoms and lab tests was evaluated.

\section{RESULTS}

Fever observed only in six patients (1.6\%). It was associated with significantly higher CDEIS and UCEIS ( $p=0.02$ and $p<0.001$, respectively). Also, diarrhea was correlated with significantly higher UCEIS $(p<0.001)$. The mean fecal calprotectin was $647.64 \pm 409.37 \mu \mathrm{g} / \mathrm{g}$ in CD and $567.30 \pm 342.49$ $\mu \mathrm{g} / \mathrm{g}$ in UC patients. Higher calprotectin level was observed in patients with higher CRP level $(p=$ 0.001 ), erythrocyte sedimentation rate (ESR) level, CDEIS, and UCEIS $(r=0.438 ; 0.473$; and 0.517 ; respectively, all with $p<0.001$ ).

\section{CONCLUSION}

Our study showed that although fever and diarrhea are associated with higher endoscopic severity scores in patients with IBD, no clinical symptom could reliably predict the endoscopic results, alone. Furthermore, higher fecal calprotectin level is associated with higher ESR and C reactive protein levels, CDEIS, and UCEIS.

\section{KEYWORDS:}

Inflammatory bowel diseases, Crohn's Disease Endoscopic Index of Severity, Ulcerative Colitis Endoscopic Index of Severity, Fecal calprotectin

\section{Please cite this paper as:}

Soleymani S, Moradkhani A, Eftekhari M, Rahmanian F, Moosavy SH. Correlation between Clinical Symptoms and Lab Tests with Endoscopic Severity Indexes in Patients with Inflammatory Bowel Diseases. Middle East J Dig Dis 2020;12: 162-170. doi: 10.34172/ mejdd.2020.178.

\section{INTRODUCTION}

Inflammatory bowel disease (IBD) is a group of chronic inflammatory conditions involving the colon and small intestine. Two major types of this disorder include Crohn's disease (CD) and ulcerative colitis (UC). ${ }^{1,2}$ Either of them is characterized by an idiopathic, chronic, relapsing, inflammatory 
condition, which is immunologically mediated. ${ }^{3}$ Although $\mathrm{CD}$ could involve any portion of the gastrointestinal (GI) tract, patients with CD are usually presented with inflammatory changes of the distal small intestine and proximal colon. ${ }^{4}$ These inflammatory alterations are accompanying symptoms, including diarrhea (which could turn into bloody diarrhea in case of severe intestinal inflammation), fever, weight loss, and abdominal pain. ${ }^{5}$ On the other hand, UC primarily affects the colonic mucosa, especially its distal part. Patients suffering from $\mathrm{UC}$ are usually presented with increased stool frequency, abdominal pain, and rectal bleeding with a relapsingremitting course. ${ }^{6,7}$

Endoscopy is fundamental for diagnosis, evaluation of activity, and management of patients with IBD. It could differentiate between CD and US and monitor the course of treatment. ${ }^{8,9}$ Several different scoring systems have been described over the years for the endoscopic evaluation of the severity of DC and UC. ${ }^{8}$ The Crohn's Disease Endoscopic Index of Severity (CDEIS) and the Ulcerative Colitis Endoscopic Index of Severity (UCEIS) are two validated endoscopic criteria to assess $\mathrm{CD}$ and $\mathrm{UC}$, respectively. ${ }^{9,10}$ The former index is a complex scoring system developed by Mary and colleagues, which is not very practical outside of randomized controlled trials, but could be used to monitor endoscopic response to treatment in patients with CD. ${ }^{11,12}$ The latter, first reported by Travis and co-workers in 2012 , is an easy scoring system, which could be used to predict UC outcome. ${ }^{13-15}$

We conducted this study to evaluate the correlation between clinical symptoms and lab tests with endoscopic severity indexes in patients with IBD.

\section{MATERIALS AND METHODS}

\section{Study design and setting}

This analytical observational study was performed at Shahid Mohammadi Hospital, affiliated to Hormozgan University of Medical Sciences in 2016-2017. It was approved by the ethics board of the University. The research was carried out according to the Helsinki Declaration, and written informed consent was obtained from all participants before enrollment.

\section{Participants}

373 consecutive patients with IBD (either CD or UC) referred to Shahid Mohammadi Hospital were included in this study. The diagnosis of IBD was based on clinical symptoms and previous colonoscopy. The exclusion criteria were: patients' desire as not to participate in the study, incomplete filling of questionnaires, concomitant illnesses such as infection, malignancy, or other GI diseases, pregnancy, regular alcohol or aspirin use, treatment with antibiotics or cytotoxic drugs, and non-steroidal anti-inflammatory drug (NSAID) use for more than twice a week.

\section{Method}

Patients' demographic information, including age, sex, and disease duration was obtained from all patients. The clinical symptoms (e.g. the presence of abdominal pain, fever, diarrhea, rectal bleeding, etc.) at admission time were also reported. C-reactive protein (CRP) and erythrocyte sedimentation rate (ESR) were tested for all patients. CRP was reported as $-(\mathrm{CRP}=0), 1+(\mathrm{CRP}$ level of $0-1 \mathrm{mg} / \mathrm{L}), 2+$ (CRP level of $1-3 \mathrm{mg} / \mathrm{L})$, and 3 $+(\mathrm{CRP}>3 \mathrm{mg} / \mathrm{L})$. Fecal calprotectin was also evaluated by a quantitative enzyme immunoassay.

All patients underwent complete ileocolonoscopy by an experienced gastroenterologist and the CDEIS and UCEIS were calculated for CD and UC patients, respectively. For the CDEIS, the presence of mucosal superficial and deep ulcers, the extent of surface involved by the disease and ulceration, and the presence of ulcerated or no ulcerated stenosis were recorded in five segments (i.e. rectum, sigmoid colon and descending colon, transverse colon, cecum and ascending colon, and terminal ileum). The CDEIS ranged from 0 to 44 , with a higher score indicating more severe disease. ${ }^{10}$ The UCEIS was calculated as a simple sum consisted of the vascular pattern (scored 0-2), bleeding (scored 0-3), and erosions and ulcers (scored $0-3$ ). It ranged from 0 to 8 with zero, meaning normal mucosal appearance and higher scores indicated more severe disease. ${ }^{9}$ Detailed calculation of CDEIS and UCEIS is demonstrated in tables 1 and 2, respectively.

\section{Statistical analysis}

Statistical analysis was performed by SPSS software version 23 (SPSS Inc., Chicago, IL, USA). Data were analyzed using descriptive statistical tests, including 
Table 1: Crohn's Disease Endoscopic Index of Severity (CDEIS) calculation

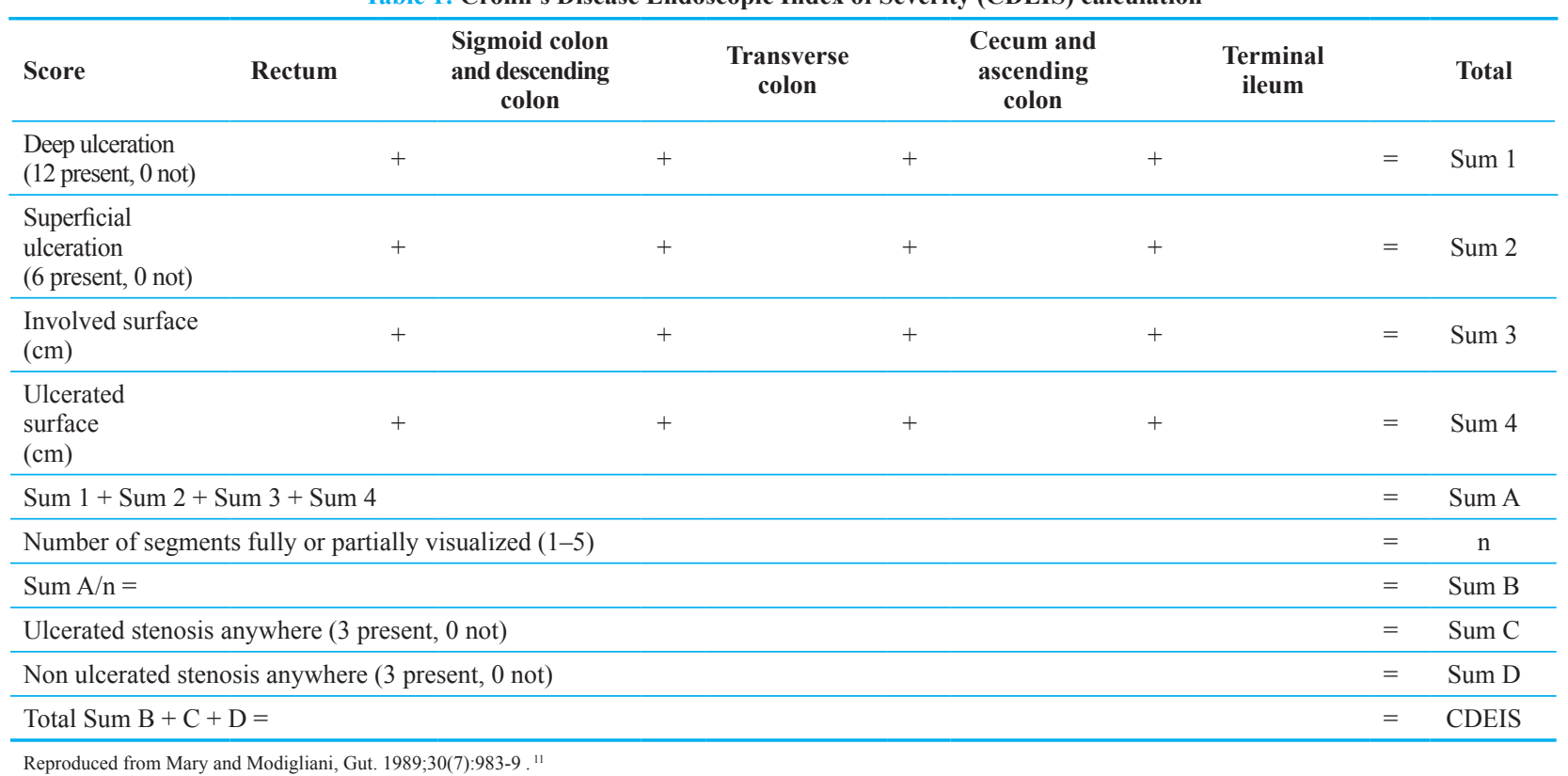

Table 2: Ulcerative Colitis Endoscopic Index of Severity (UCEIS) calculation

\begin{tabular}{|c|c|c|}
\hline Descriptor & Likert scale (anchor point) & Definition \\
\hline \multirow{3}{*}{ Vascular pattern } & Normal (0) & Normal vascular patterns \\
\hline & Patchy obliteration (1) & Patchy obliteration of vascular pattern \\
\hline & Obliterated (2) & Complete obliteration of vascular pattern \\
\hline \multirow{4}{*}{ Bleeding } & None $(0)$ & No visible blood \\
\hline & Mucosal (1) & Some spots or streaks of coagulated blood on the surface of the mucosa \\
\hline & Luminal mild (2) & Some free liquid blood in the lumen \\
\hline & $\begin{array}{l}\text { Luminal moderate or severe } \\
\qquad(3)\end{array}$ & $\begin{array}{l}\text { Frank blood in the lumen ahead of the endoscope or visibly oozing from the } \\
\text { mucosa after washing intraluminal blood, or visibly oozing from a hemor- } \\
\text { rhagic mucosa }\end{array}$ \\
\hline \multirow{4}{*}{ Erosion and ulcers } & None $(0)$ & Normal mucosa \\
\hline & Erosions (1) & Tiny $(<5 \mathrm{~mm})$ defects in the mucosa of a white or yellow color with a flat edge \\
\hline & Superficial ulcer (2) & $\begin{array}{l}\text { Larger ( }>5 \mathrm{~mm} \text { ) defects in the mucosa, which are discrete fibrin covered } \\
\text { ulcers when compared with erosions but remain superficial }\end{array}$ \\
\hline & Deep ulcer (3) & Deeper excavated defects in the mucosa with slightly raised edge \\
\hline
\end{tabular}

Reproduced from Travis et al., Gut. 2012 Apr 1; 61(4):535-42 (reference 13) and Gastroenterology 2013 Nov 1; 145(5):987-95. ${ }^{14}$

frequency, percentage, mean and standard deviation, as well as the independent $t$ test. The significant threshold was considered to be less than 0.05 .

\section{RESULTS}

Patients' demographics are demonstrated in table 3. Of the 373 patients in this study, 198 were women (53.1\%), and 175 were men (46.9\%). The mean age of the participants was $37.29 \pm 12.69$ years, and the mean duration of IBD after diagnosis was $30.23 \pm 21.92$ months. 74 patients had CD (19.8\%) and 299 patients had UC (80.2\%).

As it is shown in table 4, fever was reported in six patients $(1.6 \%)$ out of the 373 patients, diarrhea in 276 patients (74\%), rectal bleeding in 83 patients (22.3\%), and abdominal pain in 112 patients $(30 \%)$. Anal pain and discharge were reported only in patients with $\mathrm{CD}$. Anal pain was reported in $22(29.7 \%)$, and anal discharge was 
Table 3: Participants' demographics

\begin{tabular}{lccc}
\hline Characteristic & N & Mean & Std. Deviation \\
\hline Age, y & 373 & 37.29 & 12.69 \\
\hline Duration, m & 373 & 30.23 & 21.92 \\
\hline \multicolumn{2}{l}{ N } & \multicolumn{2}{c}{ Percent } \\
\hline Characteristic & N & \\
\hline Sex & & \multicolumn{2}{c}{46.9} \\
\hline Male & 175 & 53.1 \\
\hline Female & 198 & & \\
\hline Type & & & \\
\hline Ulcerative colitis & 299 & & 80.2 \\
\hline Crohn's & 74 & & 19.8 \\
\hline
\end{tabular}

positive in $15(20.3 \%)$ of the 74 patients with CD.

As it is shown in table 5, higher CRP (27\% and 5.4\% of patients with $2+$ and $3+$ CRP level in patients with CD compared with $14 \%$ and $1.7 \%$ in patients with UC) and ESR levels $(38.65 \pm 14.56 \mathrm{~mm} / \mathrm{hr}$ compared with $31.56 \pm 8.56 \mathrm{~mm} / \mathrm{hr})$ were associated with $\mathrm{CD}(p=0.007$ and 0.001 , respectively). The mean fecal calprotectin was $647.64 \pm 409.37 \mu \mathrm{g} / \mathrm{g}$ in patients with $\mathrm{CD}$ and 567.30 $\pm 342.49 \mu \mathrm{g} / \mathrm{g}$ in patients with UC. We observed no significant difference between the patients with UC and $\mathrm{CD}$ regarding the calprotectin levels.

We evaluated the correlation between fecal calprotectin and other measures (table 6). As it is demonstrated, there was no association between calprotectin level and sex, age, and disease duration. Higher calprotectin level was observed in patients with $2+$ and $3+\mathrm{CRP}$ level $(845.59 \pm 359.26 \mu \mathrm{g} / \mathrm{g}$ and $898.33 \pm 252.75 \mu \mathrm{g} / \mathrm{g}$, respectively with $p=0.001$ ). Also, higher calprotectin level was related to higher ESR level, CDEIS, and UCEIS $(p<0.001, \mathrm{r}=0.438 ; p<0.001$, $\mathrm{r}$ $=0.473$; and $p<0.001, \mathrm{r}=0.517$, respectively)

The mean CDEIS and UCEIS were $38.65 \pm 14.56$ and $4.87 \pm 1.34$, respectively (table 5 ). In patients with $\mathrm{CD}$, we observed a significantly higher CDEIS only in the presence of fever $(35.00 \pm 0.00$ compared with $32.18 \pm$ 8.65 , with $p=0.02$ ) (table 7). In table 3 , the relationship between each symptom of the patients with UC with the score of UCEIS has been investigated. In patients with UC, fever and diarrhea were associated with significantly higher UCEIS (7.40 \pm 0.89 in febrile patients compared with $4.83 \pm 1.31$, and $5.03 \pm 1.35$ if the diarrhea was reported compared with $4.08 \pm .98$, both with $p<0.001$ ) (table 8).
Table 4: Clinical symptoms of the participants

\begin{tabular}{lcc}
\hline Characteristic & N & Percent \\
\hline Fever & 6 & 1.6 \\
\hline Yes & 367 & 98.4 \\
\hline No & & \\
\hline Diarrhea & 276 & 74 \\
\hline Yes & 97 & 26 \\
\hline No & & \\
\hline Rectal bleeding & 83 & 22.3 \\
\hline Yes & 290 & 77.7 \\
\hline No & & 30 \\
\hline Abdominal pain & 112 & 70 \\
\hline Yes & 261 & \\
\hline No & & 56 \\
\hline Anal pain & 22 & 96.1 \\
\hline Yes & 351 & \\
\hline No & & \\
\hline Anal discharge & & \\
\hline Yes & & \\
\hline No & & \\
\hline
\end{tabular}

\section{DISCUSSION}

Colonoscopy is a time consuming and costly procedure in patients with IBD. Therefore, it is important to find a criterion that can be used to monitor treatment and disorder activity with a relatively low cost while being non-invasive. The aim of this study was to investigate the relationship between clinical symptoms and lab tests with the endoscopic severity score in patients with $\mathrm{CD}$ and $\mathrm{UC}$ to evaluate whether they could be used as an alternative to predict the endoscopic result in such patients. In patients with $\mathrm{CD}$, the correlation of symptoms such as anal pain and discharge, fever, diarrhea, rectal bleeding, and abdominal pain with CDEIS was evaluated. In patients with UC, the association of clinical symptoms, including diarrhea, fever, abdominal pain, and rectal bleeding with UCEIS was investigated. According to the findings of our study, fever in patients with $\mathrm{CD}$ and diarrhea and fever in patients with UC were associated with CDEIS and UCEIS, respectively. As for laboratory tests, higher fecal calprotectin level was correlated with higher ESR, CRP, CDEIS, and UCEIS. Finally, CD was associated with higher CRP and ESR levels compared with UC.

Several studies have described the importance of endoscopic severity indexes in predicting treatment 
Table 5: The Patients' lab test and endoscopic severity indexes

\begin{tabular}{|c|c|c|c|c|}
\hline Measures & All patients & Patients with CD & Patients with UC & P-value \\
\hline \multicolumn{5}{|c|}{ CRP, n (\%) } \\
\hline- & $48(12.9 \%)$ & $6(8.1 \%)$ & $42(14 \%)$ & \multirow{4}{*}{0.007} \\
\hline $1+$ & $254(68.1 \%)$ & $44(59.5 \%)$ & $210(70.2 \%)$ & \\
\hline $2+$ & $62(16.6 \%)$ & $20(27 \%)$ & $42(14 \%)$ & \\
\hline $3+$ & $9(2.4 \%)$ & $4(5.4 \%)$ & $5(1.7 \%)$ & \\
\hline \multicolumn{5}{|c|}{ ESR $(\mathrm{mm} / \mathrm{hr})$, mean \pm Std. Deviation } \\
\hline & $32.96 \pm 10.69$ & $38.65 \pm 14.56$ & $31.56 \pm 8.56$ & 0.001 \\
\hline \multicolumn{5}{|c|}{ Calprotectin $(\mu \mathrm{g} / \mathrm{g})$, mean \pm Std. Deviation } \\
\hline & $583.36 \pm 357.72$ & $647.64 \pm 409.37$ & $567.30 \pm 342.49$ & 0.084 \\
\hline \multicolumn{5}{|c|}{ Endoscopic severity index [CDEIS in CD patients and UCEIS in UC patients], mean \pm Std. Deviation } \\
\hline & & $38.65 \pm 14.56$ & $4.87 \pm 1.34$ & \\
\hline
\end{tabular}

Table 6: Calprotectin relation with other measurements

\begin{tabular}{|c|c|c|c|}
\hline Measures & Mean & Std. Deviation & $p$ value \\
\hline \multicolumn{4}{|l|}{ CRP } \\
\hline- & 248.33 & 80.77 & \multirow{4}{*}{0.001} \\
\hline $1+$ & 572.46 & 334.91 & \\
\hline $2+$ & 845.59 & 359.26 & \\
\hline $3+$ & 898.33 & 252.75 & \\
\hline \multicolumn{4}{|l|}{$\operatorname{Sex}$} \\
\hline Male & 368.07 & 362.00 & \multirow{2}{*}{0.442} \\
\hline Female & 596.80 & 354.30 & \\
\hline Measures & $p$ value & \multicolumn{2}{|c|}{ Regression analysis } \\
\hline Age & 0.971 & \multicolumn{2}{|c|}{0.971} \\
\hline Duration & 0.708 & \multicolumn{2}{|c|}{0.708} \\
\hline ESR & $<.001$ & \multicolumn{2}{|c|}{$<.001$} \\
\hline CDEIS & $<.001$ & \multicolumn{2}{|c|}{$<.001$} \\
\hline UCEIS & $<.001$ & \multicolumn{2}{|c|}{$<.001$} \\
\hline
\end{tabular}

CRP: C-reactive protein

ESR: erythrocyte sedimentation rate

CDEIS: Crohn's Disease Endoscopic Index of Severity

UCEIS: Ulcerative Colitis Endoscopic Index of Severity

outcomes in patients with IBD. According to Ferrante and colleagues, ${ }^{10}$ a $50 \%$ decrease from baseline in CDEIS in week 26 after the medical intervention was associated with 50-week sustained clinical remission in patients with $\mathrm{CD}$, with a sensitivity and specificity of $56 \%$ and $65 \%$, respectively. Of note, Landi and others ${ }^{16}$ suggested that CDEIS had a slight application in clinical practice because of its complex and time-consuming manner. As for UCEIS, Ikeya and co-workers 9 reported that UCEIS is a superior method to foretell the long-term prognosis of treatment, and it reflects the true clinical outcome after medical intervention due to its ability to distinguish between deep and shallow ulcer in the early stages of the healing process. Corte and colleagues ${ }^{17}$ reported that UCEIS $>5$ at the admission time was associated with a higher possibility of using rescue therapy or colectomy on the course of treatment. According to this study, the UCEIS of $>7$ at admission is a reliable predictor for early 
Table 7: The relation between clinical symptoms and CDEIS in patients with Crohn's disease

\begin{tabular}{|c|c|c|c|c|}
\hline Symptoms & $\mathbf{N}$ & $\begin{array}{c}\text { Mean } \\
\text { CDEIS }\end{array}$ & $\begin{array}{c}\text { Std. } \\
\text { Deviation }\end{array}$ & $\begin{array}{c}p \\
\text { value }\end{array}$ \\
\hline \multicolumn{5}{|l|}{ Fever } \\
\hline Yes & 1 & 35 & 0.00 & \multirow{2}{*}{0.020} \\
\hline No & 72 & 32.18 & 8.65 & \\
\hline \multicolumn{5}{|l|}{ Diarrhea } \\
\hline Yes & 27 & 34.56 & 9.43 & \multirow{2}{*}{0.127} \\
\hline No & 46 & 31.24 & 8.49 & \\
\hline \multicolumn{5}{|c|}{ Rectal bleeding } \\
\hline Yes & 14 & 36.36 & 9.32 & \multirow{2}{*}{0.070} \\
\hline No & 59 & 31.54 & 8.66 & \\
\hline \multicolumn{5}{|c|}{ Abdominal pain } \\
\hline Yes & 53 & 33.21 & 9.20 & \multirow{2}{*}{0.251} \\
\hline No & 20 & 30.50 & 8.07 & \\
\hline \multicolumn{5}{|l|}{ Anal pain } \\
\hline Yes & 22 & 34.05 & 10.26 & \multirow{2}{*}{0.325} \\
\hline No & 51 & 31.78 & 8.31 & \\
\hline \multicolumn{5}{|c|}{ Anal discharge } \\
\hline Yes & 15 & 33.67 & 10.18 & \multirow{2}{*}{0.563} \\
\hline No & 58 & 32.16 & 8.65 & \\
\hline
\end{tabular}

identification of high-risk patients who would require rescue therapy.

Few studies have described the association between clinical symptoms and endoscopic severity indexes. In the study by Durko and co-workers, ${ }^{18}$ CDEIS was correlated with histological findings and not the clinical scales. According to Travis and others, ${ }^{15}$ stool frequency and rectal bleeding were associated with the endoscopic severity index in patients with UC with a correlation coefficient of 0.76 and 0.82 , respectively.

In the present study, among clinical symptoms, only fever in patients with $\mathrm{CD}$ and fever and diarrhea in patients with UC were associated with higher endoscopic severity indexes. The correlation between fever and either endoscopic severity indexes could not be considered a reliable conclusion as we observed fever in a small portion of the participants (one febrile in 74 patients with CD and five in 299 patients with UC) and due to the small febrile population, this finding could not be a reliable conclusion to make a decision on, and it is necessary to be confirmed with further studies with more febrile cases.

As for diarrhea in UC cases, diarrhea and fever associated with positive inflammatory biomarkers could
Table 8: The relation between clinical symptoms and UCEIS in patients with ulcerative colitis

\begin{tabular}{|c|c|c|c|c|}
\hline Symptoms & $\mathbf{N}$ & $\begin{array}{l}\text { Mean } \\
\text { CDEIS }\end{array}$ & $\begin{array}{c}\text { Std. } \\
\text { Deviation }\end{array}$ & $p$ value \\
\hline \multicolumn{5}{|l|}{ Fever } \\
\hline Yes & 5 & 7.40 & .89 & \multirow{2}{*}{$<0.001$} \\
\hline No & 294 & 4.83 & 1.31 & \\
\hline \multicolumn{5}{|l|}{ Diarrhea } \\
\hline Yes & 249 & 5.03 & 1.35 & \multirow{2}{*}{$<0.001$} \\
\hline No & 50 & 4.08 & .98 & \\
\hline \multicolumn{5}{|c|}{ Rectal bleeding } \\
\hline Yes & 69 & 5.17 & 1.65 & \multirow{2}{*}{0.391} \\
\hline No & 230 & 4.78 & 1.23 & \\
\hline \multicolumn{5}{|l|}{$\begin{array}{l}\text { Abdominal } \\
\text { pain }\end{array}$} \\
\hline Yes & 58 & 5.17 & 1.55 & \multirow{2}{*}{0.372} \\
\hline No & 241 & 4.80 & 1.28 & \\
\hline
\end{tabular}

be interpreted as a sign of disease activity, but in 30\% of patients with inactive IBD, diarrhea alone might be a symptom of irritable bowel syndrome (IBS). On the contrary to our study, several studies have described UCEIS improvement after medical intervention in some cases, despite experiencing sustained rectal bleeding and stool frequency. ${ }^{9}$ In a meta-analysis by Narula and colleagues, ${ }^{19}$ abnormal stool frequencies was reported despite endoscopic remission. Several reasons have been described to explain the discrepancy between endoscopic severity indexes and elevated stool frequency. Some studies have found abnormal histological findings despite the presence of clinical and endoscopic remission. ${ }^{20-22}$ IBSlike symptoms have been observed in some patients with quiescent IBD due to occult inflammation. ${ }^{23}$ Other causes are; damage to the enteric nervous system, rectal hypersensitivity as a result of mast cell activation, and alteration of the colon and rectum length and caliber. ${ }^{24-28}$

Based on the above-mentioned issues, we could not mark any of the clinical symptoms as a reliable predictor of endoscopic results.

Some studies have also suggested that factors such as CRP are effective in predicting IBD activity. ${ }^{29}$ In the study by Karoui and co-workers, ${ }^{30} \mathrm{CD}$ activity index score was associated with CRP $(\mathrm{r}=0.302 ; p=0.001)$, and CRP of $19 \mathrm{mg} / \mathrm{L}$ seemed to be a reliable marker to diagnose moderate to severe $\mathrm{CD}$ with a sensitivity of $76.4 \%$ and a specificity of $56.2 \%$. In the review article 
by Mosli and co-workers, ${ }^{31}$ the pooled data showed a sensitivity and specificity of 0.49 and 0.92 , respectively, for CRP regarding the assessment of patients with IBD. In the study by Schoepfer and colleagues, ${ }^{32}$ the elevated CRP levels were associated with higher CD severity ( $\mathrm{r}$ $=0.53$ ). In the present study, similar to other studies, inflammatory biomarkers were associated with $\mathrm{CD}$, and more cases with elevated CRP and ESR levels were observed among the patients with CD.

Recently, fecal markers have been studied for assessing intestinal inflammation in patients with IBD with some success. These markers include lactoferrin, polymorphonuclear neutrophil (PMN) elastase, and calprotectin. These three markers could evaluate disease activity in either CD or UC and differentiate IBD and IBS even when there is no disease activity. Either of these markers seems to have superior diagnostic accuracy compared with CRP in patients with IBD. Among these three, fecal calprotectin was also shown to be a useful screening tool for identifying patients suspected of IBD, and it has a better correlation with CDEIS and histopathological findings of inflammation compared with clinical symptoms. ${ }^{33-38}$ In the present study, the fecal calprotectin level was associated with endoscopic severity of CD and UC evaluated by CDEIS and UCEIS, respectively. Higher fecal calprotectin was also associated with positive inflammatory biomarkers, i.e. ESR and CRP. These findings are in line with the results of other studies regarding the role of fecal calprotectin in patients with IBD. According to Schoepfer and colleagues, ${ }^{32}$ among several markers, fecal calprotectin had the closest association with endoscopic severity in patients with CD (evaluated by Simple Endoscopic Score for Crohn's disease (SES-CD)) with a correlation coefficient of 0.75 . Also, it was the only marker with the ability to delineating between inactive and active cases. In the study by Mosli and others, ${ }^{31}$ fecal calprotectin showed to be more sensitive than CRP in patients with IBD ( 0.88 compared with 0.49 ) and with better specificity in UC than CD (0.79 compared with 0.68). Furthermore, fecal calprotectin has been shown to have a significant association with mucosal healing in patients with IBD, and a cut-off of $\leq 71 \mu \mathrm{g} / \mathrm{g}$ (with a sensitivity of $95.9 \%$ and specificity of $52.3 \%$ ) could be used as a reliable tool for evaluating mucosal healing. ${ }^{39,40}$ It should be noted that a recent study showed a better diagnostic accuracy for fecal calprotectin in UC compared with CD. ${ }^{41}$

The present study has some limitations. The main limitation was the small sample size, especially for the patients with $\mathrm{CD}$. As it was noted before, several reported symptoms, including fever, were observed in a few cases, which may have affected the results of the study. Also, it was a single-center study. Furthermore, in the present study, disease activity was based on the endoscopic findings, and the histopathological evaluation was not done. Finally, a cut-off point neither for CD nor UC was evaluated. Further multicenter studies with larger sample sizes are recommended in order to achieve more reliable results.

\section{CONCLUSIONS}

Our study showed that although fever and diarrhea are associated with higher endoscopic severity scores in patients with IBD, neither clinical symptoms could reliably predict the endoscopic results, alone. Furthermore, higher fecal calprotectin level is associated with higher ESR and CRP levels, and CDEIS, and UCEIS

\section{ACKNOWLEDGMENTS}

The present study was supported by a grant from the Vice-chancellor for Research, Hormozgan University of Medical Sciences, Iran.

\section{ETHICAL APPROVAL}

There is nothing to be declared.

\section{CONFLICT OF INTEREST}

The authors declare no conflict of interest related to this work.

\section{REFERENCES}

1. Baumgart DC, Carding SR. Inflammatory bowel disease: cause and immunobiology. Lancet 2007; 369:1627-40. doi: 10.1016/S0140-6736(07)60750-8.

2. Xavier RJ, Podolsky DK. Unravelling the pathogenesis of inflammatory bowel disease. Nature 2007;448:42734. doi: 10.1038/nature06005.

3. Sartor RB. Mechanisms of disease: pathogenesis of Crohn's disease and ulcerative colitis. Nat Clin Pract Gastroenterol Hepatol 2006;3:390-407. doi: 10.1038/ncpgasthep0528. 
4. Kucharski M, Karczewski J, Mańkowska-Wierzbicka D, Karmelita-Katulska K, Kaczmarek E, Iwanik K, et al. Usefulness of Endoscopic Indices in Determination of Disease Activity in Patients with Crohn's Disease. Gastroenterol Res Pract 2016. doi: 10.1155/2016/7896478.

5. Khanna R, Bouguen G, Feagan BG, D'Haens G, Sandborn WJ, Dubcenco E, et al. A systematic review of measurement of endoscopic disease activity and mucosal healing in Crohn's disease: recommendations for clinical trial design. Inflamm Bowel Dis 2014;20:1850-61. doi: 10.1097/MIB.0000000000000131.

6. Jharap B, Sandborn WJ, Reinisch W, D'haens G, Robinson AM, Wang W, et al. Randomised clinical study: discrepancies between patient-reported outcomes and endoscopic appearance in moderate to severe ulcerative colitis. Aliment Pharmacol Ther 2015;42:1082-92. doi: 10.1111/ apt.13387.

7. Vashist NM, Samaan M, Mosli MH, Parker CE, MacDonald JK, Nelson SA, et al. Endoscopic scoring indices for evaluation of disease activity in ulcerative colitis. Cochrane Database Syst Rev 2018;1:CD011450. doi:10.1002/14651858.cd011450.pub2

8. Moran CP, Neary B, Doherty GA. Endoscopic evaluation in diagnosis and management of inflammatory bowel disease. World J Gastrointest Endosc 2016;8:723-32. doi: 10.4253/wjge.v8.i20.723

9. Ikeya K, Hanai H, Sugimoto K, Osawa S, Kawasaki S, Iida $\mathrm{T}$, et al. The Ulcerative Colitis Endoscopic Index of Severity more accurately reflects clinical outcomes and longterm prognosis than the Mayo Endoscopic Score. J Crohns Colitis 2016;10:286-95. doi: 10.1093/ecco-jcc/jjv210

10. Ferrante M, Colombel JF, Sandborn WJ, Reinisch W, Mantzaris GJ, Kornbluth A, et al. Validation of endoscopic activity sco res in patients with Crohn's disease based on a post hoc analysis of data from SONIC. Gastroenterology 2013;145:978-86. doi: 10.1053/j. gastro.2013.08.010.

11. Mary JY, Modigliani R. Development and validation of an endoscopic index of the severity for Crohn's disease: a prospective multicentre study. Groupe d'Etudes Therapeutiques des Affections Inflammatoires du Tube Digestif (GETAID). Gut 1989;30:983-9. doi: 10.1136/ gut.30.7.983.

12. Vuitton L, Marteau P, Sandborn WJ, Levesque BG, Feagan B, Vermeire S, et al. IOIBD technical review on endoscopic indices for Crohn's disease clinical trials. Gut 2016;65:1447-55. doi: 10.1136/gutjnl-2015-309903.

13. Travis SP, Schnell D, Krzeski P, Abreu MT, Altman DG, Colombel JF, et al. Developing an instrument to assess the endoscopic severity of ulcerative colitis: the Ulcerative Colitis Endoscopic Index of Severity (UCEIS). Gut 2012;61:535-42. doi: 10.1136/gutjnl-2011-300486.
14. Travis SP, Schnell D, Krzeski P, Abreu MT, Altman DG, Colombel JF, et al. Reliability and initial validation of the ulcerative colitis endoscopic index of severity. Gastroenterology 2013;145:987-95. doi: 10.1053/j.gastro.2013.07.024.

15. Travis SP, Schnell D, Feagan BG, Abreu MT, Altman DG, Hanauer SB, et al. The impact of clinical information on the assessment of endoscopic activity: characteristics of the ulcerative colitis endoscopic index of severity [UCEIS]. $J$ Crohns Colitis 2015;9:607-16. doi: 10.1093/ecco-jcc/jjv077.

16. Landi B, Cortot A, Soule JC, René E, Gendre JP, Bories P, et al. Endoscopic monitoring of Crohn's disease treatment: a prospective, randomized clinical trial. Gastroenterology 1992;102:1647-53. doi: 10.1016/0016-5085(92)91725-j.

17. Corte C, Fernandopulle N, Catuneanu AM, Burger D, Cesarini M, White L, et al. Association between the ulcerative colitis endoscopic index of severity (UCEIS) and outcomes in acute severe ulcerative colitis. J Crohns Colitis 2015;9:376-81. doi: 10.1093/ecco-jcc/jjv047.

18. Durko Ł, Stasikowska-Kanicka OA, WagrowskaDanilewicz M, Danilewicz M, Małecka-Panas EI. An analysis of the correlation of clinical, endoscopic and histological classifications in Crohn's disease. Prz Gastroenterol 2013; 8377-82. doi: 10.5114/pg.2013.39921.

19. Narula N, Alshahrani AA, Yuan Y, Reinisch W, Colombel JF. Patient-reported outcomes and endoscopic appearance of ulcerative colitis: a systematic review and metaanalysis. Clin Gastroenterol Hepatol 2019;17:411-8. doi: 10.1016/j.cgh.2018.06.015.

20. Riley SA, Mani V, Goodman MJ, Dutt S, Herd ME. Microscopic activity in ulcerative colitis: what does it mean?. Gut 1991;32:174-8. doi: 10.1136/gut.32.2.174.

21. Rosenberg L, Lawlor GO, Zenlea T, Goldsmith JD, Gifford A, Falchuk KR, et al. Predictors of endoscopic inflammation in patients with ulcerative colitis in clinical remission. Inflamm Bowel Dis 2013;19:779-84. doi: 10.1097/MIB.0b013e3182802b0e.

22. Christensen B, Erlich J, Hanauer SB, Rubin DT. 964 agreement between deep histological remission and mucosal healing in ulcerative colitis and predictors of each outcome. Gastroenterology 2014;146: S-172. doi:10.1016/S0016-5085(14)60606-5.

23. Vivinus-Nébot M, Frin-Mathy G, Bzioueche H, Dainese R, Bernard G, Anty R, et al. Functional bowel symptoms in quiescent inflammatory bowel diseases: role of epithelial barrier disruption and low-grade inflammation. Gut 2014;63:744-52. doi: 10.1136/gutjnl-2012-304066.

24. Linden DR. Colitis is associated with a loss of intestinofugal neurons. Am J Physiol Gastrointest Liver Physiol 2012;303:G1096-104. doi: 10.1152/ajpgi.00176.2012.

25. Rumessen JJ, Vanderwinden JM, Horn T. Ulcerative colitis: ultrastructure of interstitial cells in myenteric plexus. Ultrastruct Pathol 2010;34:279-87. doi: 10.3109/01913121003770701. 
26. Bernardini N, Segnani C, Ippolito C, De Giorgio R, Colucci $\mathrm{R}$, Faussone-Pellegrini MS, et al. Immunohistochemical analysis of myenteric ganglia and interstitial cells of Cajal in ulcerative colitis. J Cell Mol Med 2012;16:318-27. doi: 10.1111/j.1582-4934.2011.01298.x.

27. van Hoboken EA, Thijssen AY, Verhaaren R, van der Veek PP, Prins FA, Verspaget HW, et al. Symptoms in patients with ulcerative colitis in remission are associated with visceral hypersensitivity and mast cell activity. Scand J Gastroenterol 2011;46:981-7. doi: 10.3109/00365521.2011.579156.

28. De Dombal FT, Geffen N, Darnborough A, Watkinson G, Goligher JC. Radiological appearances of ulcerative colitis: an evaluation of their clinical significance. Gut 1968;9:157-63. doi: 10.1136/gut.9.2.157.

29. Vermeire S, Van Assche G, Rutgeerts P. Laboratory markers in IBD: useful, magic, or unnecessary toys? Gut 2006;55:426-31. doi: 10.1136/gut.2005.069476.

30. Karoui S, Ouerdiane S, Serghini M, Jomni T, Kallel L, Fekih M, et al. Correlation between levels of C-reactive protein and clinical activity in Crohn's disease. Dig Liver Dis 2007;39:1006-10. doi: 10.1016/j.dld.2007.06.015.

31. Mosli MH, Zou G, Garg SK, Feagan SG, MacDonald JK, Chande N, et al. C-reactive protein, fecal calprotectin, and stool lactoferrin for detection of endoscopic activity in symptomatic inflammatory bowel disease patients: a systematic review and meta-analysis. Am J Gastroenterol 2015;110:802-19. doi: 10.1038/ajg.2015.120.

32. Schoepfer AM, Beglinger C, Straumann A, Trummler M, Vavricka SR, Bruegger LE, et al. Fecal calprotectin correlates more closely with the Simple Endoscopic Score for Crohn's disease (SES-CD) than CRP, blood leukocytes, and the CDAI. Am J Gastroenterol 2010;105:162-9. doi: 10.1038/ajg.2009.545.

33. KarczewskiJ, Swora-CwynarE, Rzymski P,PoniedziałekB, Adamski Z. Selected biologic markers of inflammation and activity of Crohn's disease. Autoimmunity 2015;48:318 27. doi: 10.3109/08916934.2015.1016221.

34. Mańkowska-Wierzbicka D, Swora-Cwynar E, Poniedziałek B, Adamski Z, Dobrowolska A, Karczewski J. Usefulness of selected laboratory markers in ulcerative colitis. Eur Cytokine Netw 2015;26:26-37. doi: 10.1684/ ecn.2015.0363.

35. Langhorst J, Elsenbruch S, Koelzer J, Rueffer A, Michalsen A, Dobos GJ. Noninvasive markers in the assessment of intestinal inflammation in inflammatory bowel diseases: performance of fecal lactoferrin, calprotectin, and PMN-elastase, CRP, and clinical indices. Am J Gastroenterol 2008;103:162-9. doi: 10.1111/j.15720241.2007.01556.x

36. Sipponen T, Savilahti E, Kärkkäinen P, Kolho KL, Nuutinen H, Turunen U, et al. Fecal calprotectin, lactoferrin, and endoscopic disease activity in monitoring antiTNF-alpha therapy for Crohn's disease. Inflamm Bowel Dis 2008;14:1392-8. doi: 10.1002/ibd.20490.

37. Tibble JA, Sigthorsson G, Bridger S, Fagerhol MK, Bjarnason I. Surrogate markers of intestinal inflammation are predictive of relapse in patients with inflammatory bowel disease. Gastroenterology 2000;119:15-22. doi: 10.1053 /gast.2000.8523

38. Van Rheenen PF, Van de Vijver E, Fidler V. Faecal calprotectin for screening of patients with suspected inflammatory bowel disease: diagnostic meta-analysis. BMJ 2010;341:c3369. doi: 10.1136/bmj.c3369.

39. Taghvaei T, Maleki I, Nagshvar F, Fakheri H, Hosseini $\mathrm{V}$, Valizadeh SM, et al. Fecal calprotectin and ulcerative colitis endoscopic activity index as indicators of mucosal healing in ulcerative colitis. Intern Emerg Med 2015;10:321-8. doi: 10.1007/s11739-014-1144-x

40. Vázquez-Morón JM, Pallarés-Manrique H, Machancoses FH, Ramos-Lora M, Ruiz-Frutos C. Accurate cutoffs for predicting endoscopic activity and mucosal healing in Crohn's disease with fecal calprotectin. Rev Esp Enferm Dig 2017;109:130-6. doi: 10.17235/ reed.2017.4542/2016.

41. Jusué V, Chaparro M, Gisbert JP. Accuracy of fecal calprotectin for the prediction of endoscopic activity in patients with inflammatory bowel disease. Dig Liver Dis 2018;50:353-9. doi: 10.1016/j.dld.2017.12.022. 